\title{
Is thyroid stunning clinically relevant? A retrospective analysis of 208 patients
}

\author{
O atordoamento da tireoide é clinicamente relevante? \\ Análise retrospectiva de 208 pacientes
}

Elba C. S. C. Etchebehere' ${ }^{1}$ Allan O. Santos' ${ }^{1}$, Patrícia S. Matos², Lígia V. M. Assumpção ${ }^{3}$, Maria Cecília V. L. Lima' ${ }^{1}$ Mariana C. L. Lima' ', Laura S. Ward ${ }^{4}$

${ }^{1}$ Division of Nuclear Medicine of the Department of Radiology, School of Medical Sciences, Universidade Estadual de Campinas (Unicamp), Campinas, SP, Brazil

${ }^{2}$ Department of Pathology, School of Medical Sciences, Unicamp Campinas, SP, Brazil

${ }^{3}$ Division of Endocrinology of the Department of Internal Medicine, School of Medical Sciences,

Unicamp, Campinas, SP, Brazil ${ }^{4}$ Laboratory of Molecular Cancer Genetics, School of Medical Sciences, Unicamp, Campinas, SP, Brazil
Correspondence to:

Elba C. S. C. Etchebehere

Division of Nuclear Medicine,

Faculdade de Ciências Médicas,

Universidade Estadual de Campinas

Av. Zeferino Vaz, s/n

13081-970 - Campinas, SP, Brazi

elba.etchebehere@uol.com.br

Received on Sept/12/2013

Accepted on Dec/6/2013

\begin{abstract}
Objective: Current guidelines have advised against the performance of ${ }^{131}$ I-iodide diagnostic whole body scintigraphy (dxWBS) to minimize the occurrence of stunning, and to guarantee the efficiency of radioiodine therapy (RIT). The aim of the study was to evaluate the impact of stunning on the efficacy of RIT and disease outcome. Subjects and methods: This retrospective analysis included 208 patients with differentiated thyroid cancer managed according to a same protocol and followed up for 12-159 months (mean $30 \pm 69$ months). Patients received RIT in doses ranging from 3,700 to $11,100 \mathrm{MBq}(100 \mathrm{mCi}$ to $300 \mathrm{mCi}$ ). Post-RIT-whole body scintigraphy images were performed 10 days after RIT in all patients. In addition, images were also performed 24-48 hours after therapy in 22 patients. Outcome was classified as no evidence of disease (NED), stable disease (SD) and progressive disease (PD). Results: Thyroid stunning occurred in 40 patients $(19.2 \%)$, including 26 patients with NED and 14 patients with SD. A multivariate analysis showed no association between disease outcome and the occurrence of stunning ( $p$ $=0.3476)$. Conclusion: The efficacy of RIT and disease outcome do not seem to be related to thyroid stunning. Arq Bras Endocrinol Metab. 2014;58(3):292-300
\end{abstract}

\section{Keywords}

Thyroid cancer; radioiodine therapy; radionuclide scintigraphy; stunning; ${ }^{131}$-iodide

\section{RESUMO}

Objetivo: As diretrizes atuais alertam contra a execução da cintigrafia de corpo inteiro com iodo- ${ }^{131}$ (dxWBS) para minimizar a ocorrência de atordoamento e garantir a eficiência do tratamento com radioiodo (RIT). O objetivo deste estudo foi avaliar o impacto do atordoamento sobre a eficácia do RIT e desfechos da doença. Sujeitos e métodos: Esta análise retrospectiva incluiu 208 pacientes com câncer diferenciado de tireoide submetidos ao mesmo protocolo e acompanhados por 12-159 semanas (média de $30 \pm 69$ meses). Os pacientes receberam RIT com doses variando de 3.700 a $11.100 \mathrm{MBq}(100 \mathrm{mCi}$ a $300 \mathrm{mCi})$. As imagens da cintigrafia após a RIT foram feitas 10 dias depois da RIT em todos os pacientes. Além disso, as imagens foram também obtidas após $24-48$ h em 22 pacientes. 0 desfecho foi classificado como nenhuma evidência de doença (NED), doença estável (SD) e doença progressiva (PD). Resultados: 0 atordoamento da tireoide ocorreu em 40 pacientes (19,2\%), incluindo 26 pacientes com NED e 14 pacientes com SD. A análise multivariada não mostrou associação entre o desfecho da doença e a ocorrência de atordoamento $(p=0,3476)$. Conclusão: A eficácia da RIT e o desfecho da doença não parecem estar relacionados com o atordoamento da tireoide. Arq Bras Endocrinol Metab. 2014;58(3):292-300

\section{Descritores}

Câncer de tireoide; tratamento com radioiodo; cintigrafia com radionucleotídeos; atordoamento; iodo-131 


\section{INTRODUCTION}

Differentiated thyroid cancer (DTC) may be treated by total thyroidectomy, ${ }^{131}$ I-iodide therapy (RIT), and hormone suppression therapy $(1,2)$. Prior to RIT, whole-body diagnostic scintigraphy with ${ }^{131}$ I-iodide (dxWBS) may be performed for treatment planning.

However, the performance of dxWBS, as well as the dose recommended for the procedure is controversial due to many descriptions regarding thyroid stunning. Thyroid stunning is defined as a reduction or absence of ${ }^{131}$ I-iodide uptake in the cervical region observed on post-therapy whole body scintigraphy performed after a diagnostic dose of ${ }^{131}$ I-iodide (post-RIT-WBS) (3). This phenomenon, as hypothesized, would impair the uptake of a subsequent RIT, leading to ineffective treatment (4). Therefore, some institutions have abandoned dxWBS, preferring to perform RIT with empirical doses to prevent the occurrence of thyroid stunning. Other institutions have substituted diagnostic ${ }^{131}$ I-iodide-WBS for ${ }^{123}$ I-iodide-WBS, although the costs of the latter are higher, and the stunning effect, due to the emission of Auger electrons by ${ }^{123}$ I-iodide, could be more severe than with ${ }^{131}$ I-iodide (5). However, the true nature of this phenomenon remains uncertain. Moreover, there is no clear evidence that stunning actually interferes with disease outcomes.

Conversely, dxWBS has many benefits, distinguishing patients who may actually benefit from treatment from those who should not be treated (no cervical uptake with low thyroglobulin levels; large surgical thyroid remnants; undetected distant metastases). The correct assessment of disease sites can be used to determine and program RIT without exposing the patient to the risk of ineffective empirical doses. If the Nuclear Medicine physician decides not to perform a dxWBS prior to RIT, he may have to assume legal responsibility for performing empirical treatment doses of iodine- ${ }^{-131} \mathrm{I}$ in patients without cervical ${ }^{131}$ I-iodide uptake.

This study aimed to retrospectively evaluate the clinical impact and efficacy of RIT in patients with DTC with and without stunning.

\section{SUBJECTS AND METHODS}

This retrospective study was approved by the Research Ethics Committee of the School of Medical Sciences of the Universidade Estadual de Campinas (CEP \# 1079/2009).

\section{Patients}

A total of 208 patients with differentiated thyroid carcinoma consecutively referred to our Nuclear Medicine facility for RIT from 1998 to 2012 were retrospectively reviewed.

All patients were submitted to total thyroidectomy, with or without lymph node dissection, depending on neck ultrasound and intraoperative findings, and referred for RIT. Serum thyroglobulin (Tg) levels, antithyroglobulin antibodies ( $\mathrm{TgAb})$, and TSH were obtained before and after thyroid hormone withdrawal, immediately prior to a ${ }^{131} \mathrm{I}$-iodide dxWBS. All patients were followed up with regular serum Tg, TSH and $\mathrm{TgAb}$ measurements; annual cervical ultrasonography; annual dxWBS; and other eventual diagnostic imaging modalities, such as computed tomography, ${ }^{99 \mathrm{~m}} \mathrm{Tc}$ sestamibi whole body scintigraphy, 201-thallium whole body scintigraphy, ${ }^{18} \mathrm{~F}-\mathrm{FDG}$-PET/CT (after 2008), and bone scintigraphy for a period range of 12-159 months (mean $30 \pm 69$ months). Patients with high or increasing serum Tg levels ( $>2 \mathrm{mg} / \mathrm{dL}$ ) and/or suspicious whole body scans were submitted to a thorough imaging studies.

Patients were classified according to pTNM staging for DTC $(1,2)$. Urine iodine measurements are not routinely measured in our facility.

\section{${ }^{131}$ I-Iodide DxWBS}

All patients were oriented to follow a low iodine diet for 15 days, refraining from iodide-rich substances, as well as intravenous iodide contrasts for three months prior to dxWBS. All patients received $185 \mathrm{MBq}(5$ $\mathrm{mCi}$ ) of ${ }^{131}$ I-iodide. Images were performed after 48 hours using a dual-head scintillation camera, with high-energy parallel-hole collimators. The photopeak was centered at $364 \mathrm{KeV}$ with $15 \%$ energy window level, and bed speed of $5 \mathrm{~cm}$ per minute.

\section{RIT and post-RIT-WBS}

In addition to the dxWBS, blood cell counts, serum $\mathrm{TSH}, \mathrm{Tg}, \mathrm{TgAb}$ levels and pregnancy tests were performed one week prior to RIT. All RIT were performed with TSH levels above $30 \mathrm{mUI} / \mathrm{L}$, under hypothyroidism after a 30 days suspension of thyroid hormone treatment with levothyroxine. Doses administered ranged from 3,700 MBq to $11,100 \mathrm{MBq}$ ( 100 to $300 \mathrm{mCi}$ ), as follows: $3,700 \mathrm{MBq}$ or $100 \mathrm{mCi}$ for cervical remnants only; $5,550 \mathrm{MBq}$ or $150 \mathrm{mCi}$ for lymph node metastasis; 
$7,400 \mathrm{MBq}$ or $200 \mathrm{mCi}$ for lung metastases, and 9,250 - 11,100 MBq or 250 - $300 \mathrm{mCi}$ for bone involvement.

Post-therapeutic WBS (post-RIT-WBS) was performed on all 208 patients 10 days after discharge, with the same parameters used on the dxWBS.

A subgroup of 22 patients also underwent two postRIT-WBS: one after 24-48 hours and another after 10 days. In this subgroup of patients, the bed speed of the 24-48 hour post-RIT-WBS was $10 \mathrm{~cm}$ per minute due to higher radioactivity counts.

\section{Classification of thyroid stunning}

Two experienced nuclear medicine physicians visually assessed images from the dxWBS and post-RIT-WBS. In case of discordant findings, a third nuclear medicine physician reviewed the study. The readers were blinded to other studies and clinical outcomes. They blindly classified the patients as: no stunning, partial stunning, or total stunning. The classification of stunning was performed only after the first radioiodine treatment, taking into consideration cervical uptake and eventual metastases. Subsequent treatments were not considered for the occurrence of stunning. Uptake reduction in at least one of the foci was enough to classify the patient as having thyroid stunning.

Classification of stunning was performed as follows:

1. No stunning: uptake in post-RIT-WBS was equal to uptake on the dxWBS.

2. Partial stunning: uptake in 10 days post-RITWBS was partially reduced when compared with dxWBS (Figure 1).

3. Total stunning: uptake in 10 days post-RITWBS was absent when compared with dxWBS (Figure 2).

Among the 22 patients who also underwent a postRIT-WBS 24-48 hours after discharge, there were six patients presenting a partial stunning with washout pattern: the 24-48 hours uptake post-RIT-WBS was equal to the uptake seen on dxWBS. However, 10 days postRIT-WBS, the uptake was partially reduced, as demonstrated in figure 3 .

\section{Disease status classification}

Patients were classified as: no evidence of disease (NED); stable disease (SD); and progressive disease (PD). This classification was performed one year after each RIT and at the end of the follow-up period. Thus, for example, if a patient was submitted to three RIT, he was reclassified one year after each treatment and at the end of follow-up. This classification was based on the results of the annual dxWBS; the suppressed and stimulated serum Tg levels; the neck ultrasound and on other eventual imaging data $\left({ }^{18} \mathrm{~F}-\mathrm{FDG} \mathrm{PET} / \mathrm{CT}\right.$ or ${ }^{99 \mathrm{~m}} \mathrm{Tc}$-sestamibi).

Patients were classified as NED when presenting all of the following conditions: negative annual dxWBS; negative annual cervical ultrasound; serum $\mathrm{Tg}$ levels below $1.0 \mathrm{ng} / \mathrm{mL}$ on levothyroxine and with stimulated $\mathrm{Tg}$ levels, and negative $\mathrm{TgAb}$.

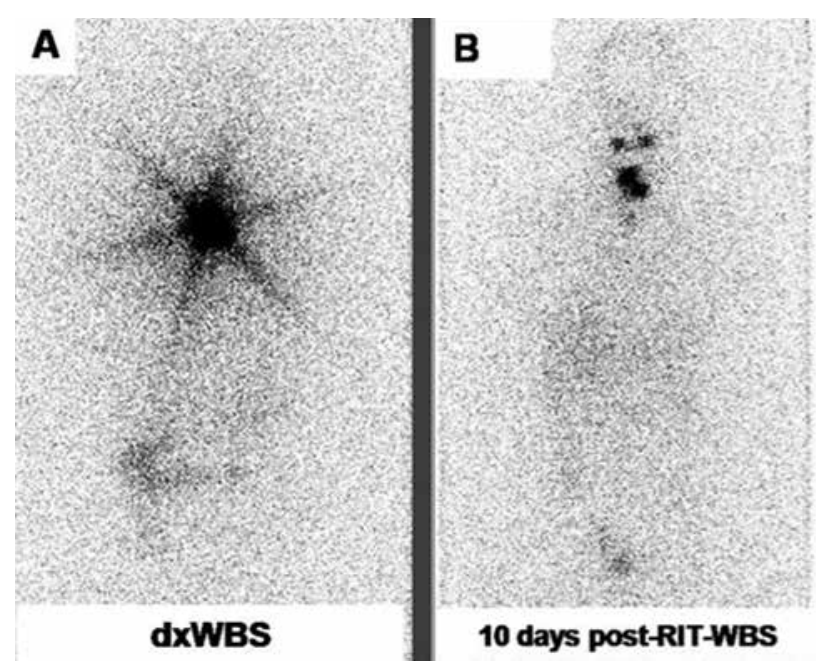

Figure 1. An example of a partial stunning. (A) ${ }^{131}$-iodide dxWBS shows increased cervical uptake. (B) Post-RIT-WBS shows a partial reduction of the cervical uptake when compared with $(\mathbf{A})$.

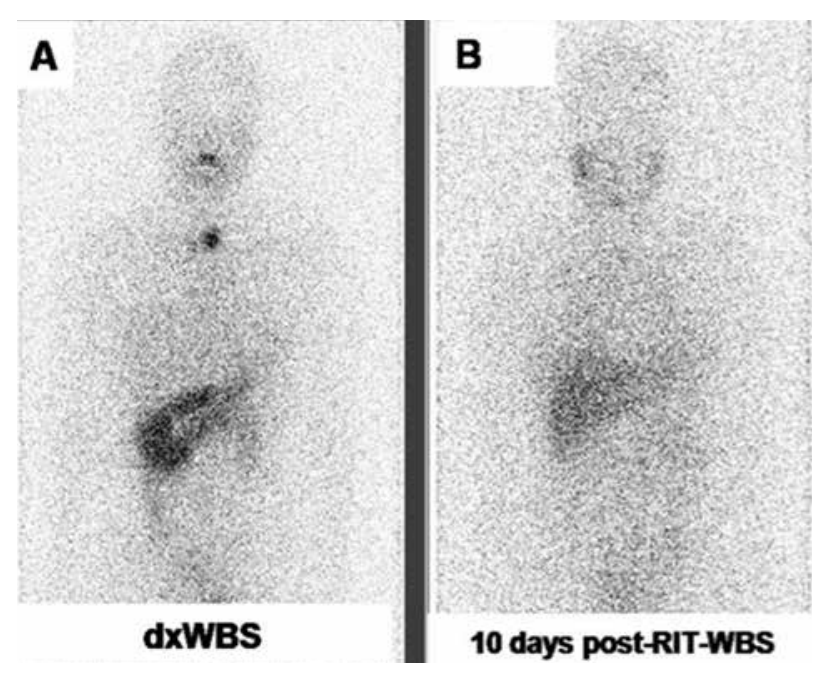

Figure 2. An example of a total stunning. (A) ${ }^{131}$-iodide dxWBS shows increased cervical uptake. (B) Post-RIT-WBS shows a no cervical uptake when compared with $(\mathbf{A})$. 

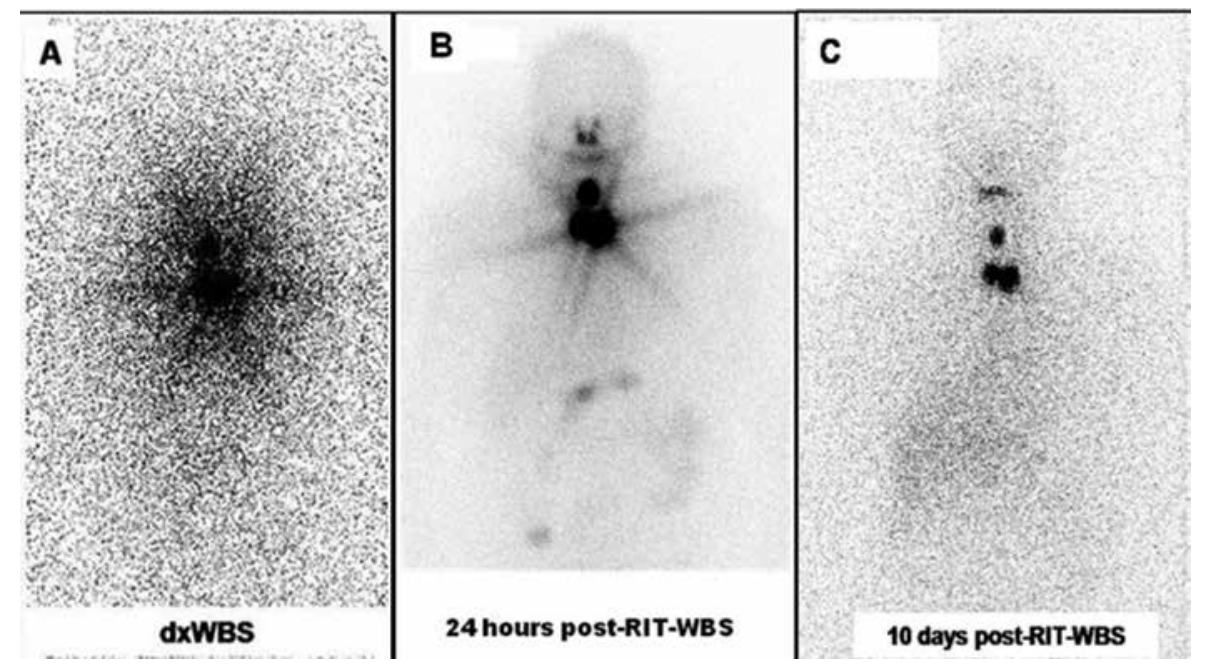

Figure 3. An example of progressive washout in a young female patient. (A) ${ }^{131}$ l-iodide dxWBS depicts markedly increased cervical uptake. (B) 24 hours post-RIT-WBS shows basically the same cervical uptake when compared with ${ }^{131}$-iodide dxWBS. (C) 10 days post-RIT-WBS shows a marked reduction in the cervical uptake.

The SD classification was based on one or more of the following conditions: persistent cervical uptake and/or metastases on the annual dxWBS or neck ultrasound; Tg non-stimulated levels above $1.0 \mathrm{ng} /$ $\mathrm{mL}$, with stimulated Tg levels above $10.0 \mathrm{ng} / \mathrm{mL}$ (but without progressive elevation); positive stable levels of TgAb.

Patients were classified as PD when presenting any of the following parameters: new metastases detected at annual dxWBS or neck ultrasound; new metastases detected in other imaging modalities; progressive increase of serum Tg levels despite RIT.

\section{Statistical analysis}

The statistical analysis was carried out using the SAS System for Windows (Statistical Analysis System, version 9.1.3, Service Pack 3. SAS Institute Inc., 20022003, Cary, NC, USA). The Pearson's chi-square test was performed to evaluate the association between the occurrence of stunning and gender, histological subtype, aggressive variants, the presence of metastases at diagnosis, Tg levels and disease status. Nonparametric analysis was performed using either the chi-square or Fisher's exact tests as indicated. The Mann-Whitney was performed to compare the presence of stunning with cumulative doses of ${ }^{131}$ I-iodide. A multiple logistic regression analysis was used to evaluate the role of the occurrence of stunning and the pTNM stage; the initial and final serum $\mathrm{Tg}$ and $\mathrm{TgAb}$ levels; tumor histology; and the presence of metastases at diagnosis. All tests were conducted with a 0.05 level of significance.

\section{RESULTS}

\section{Patient population data}

As expected, most DTC patients were female (85\%), with a mean age of $43.3 \pm 14.1$ years, as represented in table 1 . There were $178(85.6 \%)$ papillary thyroid carcinomas including 46 (22.1\%) cases of variants considered aggressive (tall cell, columnar cell, diffuse sclerosing, solid/trabecular, and insular variants); and 30 (14.4\%) follicular carcinomas (all of them widely invasive).

According to the pTNM staging, there were 105 (50.5\%) stage I patients; 43 (20.7\%) stage II; 18 (8.7\%) stage III; and $42(20.2 \%)$ stage IV patients. Among the stage IV patients, 6 were IVa and 36 were IVb. Distant metastases at diagnosis occurred in 28 (13.5\%) patients.

Only one patient did not present any cervical uptake in the dxWBS. However, RIT was performed because of high serum thyroglobulin $(89.8 \mathrm{ng} / \mathrm{mL})$ levels.

The patient doses ranged from a single dose of $3,700 \mathrm{MBq}(100 \mathrm{mCi})$ in $55.8 \%$ of the cases to a maximum of four treatment doses that cumulated to 40,700 $\mathrm{MBq}(1100 \mathrm{mCi}$ ) (Table 2). The entire patient population was submitted to initial doses only for thyroid remnants and among these, $89 \%$ of the patients were submitted to only one dose. The remaining $11 \%$ were submitted to more doses because metastatic disease developed later on during follow-up. 
Table 1. Comparison of clinical, pathological and outcome data between patients who showed stunning or not

\begin{tabular}{|c|c|c|c|c|c|}
\hline & $\begin{array}{c}\text { Mean } \pm \text { SD } \\
(\min -\max )\end{array}$ & $\begin{array}{c}\text { Total number of } \\
\text { patients (percentage) }\end{array}$ & $\begin{array}{l}\text { Non-stunning } \\
\text { (percentage) }\end{array}$ & $\begin{array}{c}\text { Stunning } \\
\text { (percentage) }\end{array}$ & $\mathrm{p}$-value \\
\hline Patients & & 208 & $168(80.8)$ & 40 (19.2) & \\
\hline Initial Tg levels & $\begin{array}{c}136.8 \pm 638.3 \\
(0.2 \text { to } 6,000)\end{array}$ & 194 & 157 (80.9) & 37 (19.1) & $\begin{array}{c}\text { Z-score }=-1.422 \\
P<0.155^{\star \star \star}\end{array}$ \\
\hline Final Tg levels & $\begin{array}{c}185.0 \pm 1053.4 \\
(0.2 \text { to } 11,480)\end{array}$ & 207 & $168(81.2)$ & 39 (18.8) & $\begin{array}{c}\text { Z-score }=-1.309 \\
P<0.191^{\star \star *}\end{array}$ \\
\hline Cumulative RIT dose & $\begin{array}{c}263.8 \pm 219.1 \\
(92 \text { to } 1,100)\end{array}$ & 208 & $168(80.8)$ & 40 (19.2) & $\begin{array}{c}\text { Z-score }=-2.239 \\
P<0.025^{\star \star \star}\end{array}$ \\
\hline Age & $43.3 \pm 14.1$ & 208 & $168(80.8)$ & 40 (19.2) & $\begin{array}{c}\text { Z-score }=-3.740 \\
P<0.0001^{\star \star \star}\end{array}$ \\
\hline \multirow[t]{2}{*}{ Gender } & Female & $177(85.1)$ & 139 (78.5) & 38 (21.5) & $0.05^{\star}$ \\
\hline & Male & $31(14.9)$ & 29 (93.5) & $2(6.5)$ & \\
\hline \multirow[t]{2}{*}{ Histology } & Follicular & $30(14.4)$ & 28 (93.3) & $2(6.7)$ & $0.059^{*}$ \\
\hline & Papillary & 178 (85.6) & $140(78.7)$ & 38 (21.3) & \\
\hline \multirow[t]{2}{*}{ PTC variant } & Aggressive & $46(22.1)$ & 43 (93.5) & $3(6.5)$ & $0.013^{\star}$ \\
\hline & Non-aggressive & $162(77.9)$ & $125(77.2)$ & 37 (22.8) & \\
\hline \multirow[t]{2}{*}{ Initial TgAb levels } & Negative & $176(84.6)$ & $145(82.4)$ & 31 (17.6) & $0.337^{\star \star}$ \\
\hline & Positive & $18(8.6)$ & $13(72.2)$ & $5(27.8)$ & \\
\hline \multirow[t]{2}{*}{ Final TgAb levels } & Negative & 195 (93.7) & $158(81.0)$ & 37 (19.0) & $0.718^{\star \star}$ \\
\hline & Positive & $13(6.3)$ & $10(76.9)$ & $3(23.1)$ & \\
\hline \multirow[t]{2}{*}{ TNM } & $1 / \|$ & $148(71.2)$ & $108(73.0)$ & $40(23.0)$ & $<0.0001^{*}$ \\
\hline & III/IV & $60(28.8)$ & $60(100)$ & $0(0)$ & \\
\hline \multirow{2}{*}{$\begin{array}{l}\text { Presence of metastases } \\
\text { at diagnosis }\end{array}$} & No & $179(86.1)$ & $142(79.3)$ & $37(20.7)$ & $0.215^{\star}$ \\
\hline & Yes & 28 (13.4) & 25 (89.3) & $3(10.7)$ & \\
\hline \multirow[t]{3}{*}{ Clinical outcome } & NED & 121 (58.2) & 95 (78.5) & 26 (23.5) & $0.34^{\star \star \star \star}$ \\
\hline & SD & $64(30.8)$ & 50 (78.1) & $14(21.9)$ & \\
\hline & PD & 23 (11.1) & $23(100)$ & $0(0)$ & \\
\hline
\end{tabular}

* Pearson's Chi-Square Test; ${ }^{* \star}$ Fisher's Exact Test; ${ }^{\star \star \star}$ Mann-Whitney U Test; ${ }^{\star \star \star \star}$ Multiple Logistic Regression Analysis.

Table 2. Initial radioiodine therapy doses in the entire patient population, according to the presence and region of metastases

\begin{tabular}{lccc}
\hline & Location of uptake & $\mathbf{M B q}(\mathbf{m C i})$ & $\begin{array}{c}\text { Total number of patients } \\
\text { (percentage) }\end{array}$ \\
\hline & Cervical uptake without lymph node metastases & $3,700(100)$ & $116(55.8)$ \\
Initial radioiodine therapy & Lymph node metastases & $5,550(150)$ & $70(33.7)$ \\
dose in MBq & Lung metastases & $7,400-9,250(200-250)$ & $21(10.0)$ \\
& Bone metastases & $>9,250$ (above 250) & $1(0.5)$ \\
\hline
\end{tabular}

\section{Thyroid stunning}

There was no inter-observer variability in any of the studies. Thyroid stunning occurred in 40 patients $(19.2 \%)$ (Table 1$)$. Thirty-four out of these patients $(85 \%)$ were classified as partial stunning and $6(15 \%)$ were classified as total stunning. There was a significant association between stunning and gender, which was more common in females, and may be related to sample size ( $\mathrm{p}=0.05$;
Pearson's Chi-Square test). However, a significant inverse relationship between stunning and age was noted $(\mathrm{Z}=-3.74 ; \mathrm{p}<0.000001 ;$ Mann-Whitney test). Younger patients tended to have more stunning effects than older patients.

There was no association between stunning and the histological classification ( $\mathrm{p}=0.059$; Pearson's ChiSquare test). However, we observed that nonaggressive variants of papillary thyroid carcinomas presented 
stunning more frequently then aggressive variants $(\mathrm{p}=0.013$; Pearson's Chi-Square test). In addition, the phenomenon was more frequent in pTNM stages I and II than in stages III and IV patients ( $\mathrm{p}<0.001$; Pearson's Chi-Square test) (Table 1).

The initial serum $\mathrm{Tg}$ levels (before thyroid hormone withdrawal) were of $136.8 \pm 638.3$ (mean \pm standard deviation) and ranged from 0.2 to 6000.0 . There was no association between stunning and initial serum $\mathrm{Tg}$ levels $(\mathrm{Z}=-1.422 ; \mathrm{p}=0.155$; Mann-Whitney test $)$.

Final serum $\mathrm{Tg}$ levels were of $185.0 \pm 1053.4$ (mean \pm standard deviation) and ranged from 0.2 to 11480.0 . There was no association between stunning and final serum Tg levels $(Z=-1.309 ; p=0.191$; Mann-Whitney test).

No associations were noted between stunning and initial serum $\operatorname{TgAb}$ levels as well $(\mathrm{p}=0.337$; Fisher's exact test); follow-up TgAb levels ( $\mathrm{p}=0.718$; Fisher's exact test); disease recurrence ( $\mathrm{p}=1.000$; Fisher's exact test); or the presence of metastases at diagnosis $(\mathrm{p}=$ 0.215; Pearson's chi-square test).

The RIT cumulative doses were of $263.8 \pm 219.1$ $\mathrm{mCi}$ and ranged from 92 to $1100 \mathrm{mCi}$. Stunning did not occur in patients who required more RITs $(\mathrm{p}=$ 0.020; nonparametric Mann-Whitney test) or higher cumulative doses ( $\mathrm{p}=0.025$; nonparametric MannWhitney test). Thus, stunning did not occur in patients who were followed-up for a longer period of time due to PD ( $\mathrm{p}=0.002$; nonparametric Mann-Whitney test) (Table 1).

\section{Disease status data}

One year after the first RIT, patients were classified according to the disease status, as follows: 127 NED patients $(61.1 \%), 59$ SD patients $(28.4 \%)$, and $22 \mathrm{PD}$ patients $(10.5 \%)$. Six patients $(2.9 \%)$ recurred (3 patients after two years of the first RIT and 3 patients after two years of the second RIT). Therefore, patients were reclassified as: NED - 121 patients $(58.2 \%)$, SD - 64 patients $(30.8 \%)$ and $\mathrm{PD}-23$ patients (11.1\%).

In the NED group, $21.5 \%(26 / 121)$ of the patients presented stunning, while in the SD group, stunning occurred in $21.8 \%(14 / 64)$ of the cases. None of the PD patients presented stunning.

Multiple logistic regression analysis showed that the presence of stunning had no association with gender type nor with pTNM stages III and IV, the presence of metastasis or Tg levels. In addition, stunning occurrence had no impact on disease outcome $(\mathrm{p}=0.33)$.

\section{DISCUSSION}

There is no agreement whether to perform diagnostic whole-body scintigraphy (dxWBS) prior to radioiodine therapy (RIT) or not in patients with well-differentiated thyroid cancer. Numerous authors and organizations have argued either to perform dxWBS prior to RIT (6-8), or not to perform it $(9,10)$ in these patients. Although this is a controversial issue in the literature, recent studies published by well-known journals and several world-wide renowned institutions still consider not only that dxWBS is an essential exam, but also an important tool to better understand the stunning phenomenon. Chen and cols. (8) recommend dxWBs prior to RIT to provide the information required to prescribe an appropriate dose of ${ }^{131}$ I-iodide for effective treatment, stating the importance of unsuspected lymph nodes or distant metastases, which involve a significantly higher dose, besides the diagnosis of unexpected large thyroid remnants, in which a new surgery or a two-step ablation may be necessary.

Another study that supports the dxWBS prior to ablation was published by Van Nostrand and cols. (6). The authors support the performance of this exam, for it can be useful by demonstrating findings that may alter the patient management prior to RIT in the following situations: absence of ${ }^{131}$ I-iodide uptake in the thyroid bed; a significant number of foci of uptake in the thyroid bed/neck region; multiple foci in the neck outside the thyroid bed; distant metastases and/or breast uptake.

The European consensus (9) also questions the use of dxWBS prior to ablation, stating that this exam may be avoided without loss of information. However, at the same time, the authors comment that dxWBS could be performed by some centers in some situations, for example when there is uncertainty concerning the extent of thyroidectomy, for large thyroid remnants that may require new surgery, or the use of corticosteroids to avoid radiation thyroiditis. According to the editorial by McDougall (11), the European consensus acknowledges that patient information regarding stage obtained after RIT is contrary to "good medicine" should be practiced, considering that all the diagnostic data should be obtained first and that the treatment should be based on that information.

We believe that not performing dxWBS prior to RIT reduces the quality of patient management. We frequently receive patients with very poor or no sur- 
gical description at all, many times with large thyroid remnants that may benefit from a second thyroidectomy before RIT. These large remnants may cause radiation thyroiditis if treated blindly (12). Besides, dxWBS provides important information considering not only the amount of thyroid remnants, but also a complete evaluation and diagnosis of unsuspected lymph node metastases, which require a significantly higher dose of $\operatorname{RIT}(8)$.

No cervical uptake (no remnants), on the other hand, may occur following total thyroidectomy. An ultrasound to detect the presence of absence of thyroid remnants has low sensitivity and does not substitute dxWBS for this purpose (8). Patients that are found to have no cervical uptake (no remnants) on a posttherapy WBS most likely will not benefit from RIT. Therefore, if the Nuclear Medicine physician does not perform a dxWBS prior to RIT, it is the Nuclear Medicine physician who may have to assume possible legal responsibility for performing empirical RIT in patients without cervical ${ }^{131}$ I-iodide uptake.

Thus, as McDougall again states in his editorial (11), one of the essentials of treating patients with cancer is to know the extent of the disease as accurately as possible. The authors' opinion considering the legal responsibility is exactly supported by this precaution, always searching for the best evaluation of each patient.

On the contrary, larger dosages of radioiodine may be administered at the time of ablation if regional or distant metastases are detected on a pre-ablation scan (8). In addition, the use of dxWBS prior to RIT may identify unsuspected uptake in the breast due to lactation or medication (13) and distant brain metastases (14). Patients with breast uptake should only be treated after the uptake is reduced to prevent mastitis. Brain metastases, albeit in a minority of patients, should be treated with corticosteroids or radiotherapy prior to RIT in order to prevent swelling $(13,14)$.

However, most guidelines, including the ones by the American Thyroid Association and the National Comprehensive Cancer Network, advise against the performance of dxWBS in order to minimize the occurrence of stunning and guarantee the efficiency of RIT $(1,2,15)$, even though they recognize that this phenomenon is not clearly understood and does not seem to have an impact on the patient outcome (16). Thyroid stunning is defined as a reduction or absence of ${ }^{131}$ I-iodide uptake in the cervical region observed on the post-RIT-WBS due to impairment of uptake of a subsequent RIT, leading to ineffective treatment. This phenomenon is not known to be due to post-diagnostic scan time dependent. In fact, a few studies concluded that thyroid stunning could cause a worse clinical outcome, as it is associated with the need for more RIT sessions $(4,17)$. On the contrary, other studies comparing the efficacy of radioiodine therapy between patients submitted to dxWBS prior to RIT, and patients not submitted to pretreatment scan prior to RIT failed to show differences in success rates of RIT or in patient outcomes (18-20).

The current study, although retrospective, is composed by a large cohort of patients submitted to the same management protocol and followed up for a considerable period of time (mean of 60 months). We clearly documented stunning in 40 (19.2\%) patients. Nevertheless, no difference in outcomes occurred among them, and the rest of the $168(80.8 \%)$ patients did not show stunning. It would be interesting to follow up patients for a longer period of time, considering that recurrence of thyroid cancer can occur up to 10 years after the initial treatment.

Interestingly, in six out of the 22 patients who underwent two post-RIT-WBS (after 24-48 hours and after ten days), a "partial stunning with washout" was observed. This pattern could represent faster thyroid turnover, since cervical uptake seen in the dxWBS was equal to that seen on the 24-48 hours post-RIT-WBS, and this uptake was reduced during the ten days postRIT-WBS in all these patients. Hence, thyroid stunning may actually represent, in some patients, a partial treatment effect rather than a reduction in treatment efficacy. As the effective half-life of the iodine-131 can be shorter under TSH stimuli ( $<3$ days), it may be impossible to differentiate if the reduction of thyroid activity is due to physiologic washout of iodine from the thyroid gland, or because of the stunning effect. However, our cohort of 22 patients presented activity in the liver, what might strength the hypotheses of physiologic clearance of iodine from the thyroid, as shown in figure 2. The same effect has also been observed by Sisson and cols., who demonstrated an early destructive effect of RIT when performing dxWBS after two days (21). Current imaging protocols and The Society of Nuclear Medicine and Molecular Imaging (SNMMI) guidelines recommend imaging of post-RIT-WBS four to ten days after administering RIT to enhance sensitivity (22). However, if the scans were to be performed in 
the 24-48 hours following RIT, thyroid stunning could pass unnoticed in the majority of the patients.

The weaknesses in our study include the fact that it is retrospective and, therefore, we could not compare the outcome of patients who did and did not receive dxWBS prior to treatment. Also, unfortunately, only a subset of patients (22) underwent a 24-48 hours postRIT-WBS, which we defined as "partial stunning with washout". We do not know how many other subjects would have demonstrated this finding if 24-48 hour post-RIT-WBS were performed in all patients. However, this does not lead to misclassification of the other patients, since all patients were classified as stunning according to the definition in the literature. We did not perform quantitative analysis of the images to classify the cervical uptake in the post-RIT-WBS as positive, negative, or with reduction compared to dxWBS. These findings were undisputable.

The lack of data of a control group (patients not receiving a dxWBS) and the impossibility to evaluate all the patients with 24-48 hours post-RIT-WBS apparently did not interfere with the results obtained, and this argument may be corroborated by the fact that, in the current study, none of the 23 patients (11.1\%) with progressive disease had thyroid stunning. Conversely, stunning occurred in $21.5 \%$ of patients without evidence of disease, and in $21.8 \%$ of patients with stable disease. In fact, stunning was also more likely to occur in younger patients and in those with nonaggressive variants, and this may also be related to better outcome. The patient population was also not heterogeneous as all patients were submitted to an initial dose for thyroid remnants and the majority ( $89 \%$ ) solely to this initial dose for thyroid remnants. The remaining $11 \%$ were submitted to more doses because of metastatic disease that developed later during follow-up.

Although many guidelines recommend $37-101$ $\mathrm{MBq}$ of iodine-131 dose for dxWBS in part due to stunning concerns, even with our dose of $185 \mathrm{MBq}$ we did not find any difference of outcome among groups.

Considering the use of ${ }^{131} \mathrm{I}$-iodide and its doses for $\mathrm{dxWBS}$, this is exactly the protocol still used by many institutions and in recent studies, as described by Amin and cols. (23). The option for this protocol is based on the concern that the sensitivity in the detection of foci that present ${ }^{131}$ I-iodide uptake may be reduced, and the substitution for ${ }^{123}$ I-iodide, besides its high costs, is controversial, for this radiopharmaceutical treatment could increase the so-called stunning effect, due to the emission of Auger electrons by ${ }^{123}$ I-iodide (5). The stunning effect is not well-known, as also highlighted by the American Thyroid Association and the National Comprehensive Cancer Network (16), demanding new scientific studies with methodologies utilized in the routine clinical practice for better understanding of this phenomenon.

In conclusion, the occurrence of thyroid stunning did not reduce the efficiency of radioiodine therapy and did not impact negatively on patient outcomes in the group studied. Although all the limitations of the study, mainly the lack of control group and of a longer follow-up period, dxWBS may be performed safely and when necessary in DTC patients, and post-RIT-WBS after $24-48$ hours, rather than after 10 days, should be considered.

Acknowledgments: we are grateful to Cleide Silva and Eduardo Hoehne from the Department of Statistics for their statistical analysis of the data. The São Paulo Research Foundation (Fapesp) provided financial support for this study (Protocol \#09/548663).

Disclosure: no potential conflict of interest relevant to this article was reported.

\section{REFERENCES}

1. Cooper DS, Doherty GM, Haugen BR, Kloos RT, Lee SL, Mandel SJ, et al. Revised American Thyroid Association Management Guidelines for Patients with Thyroid Nodules and Differentiated Thyroid Cancer:The American Thyroid Association (ATA) Guidelines Taskforce on Thyroid Nodules and Differentiated Thyroid Cancer. Thyroid. 2009;19:1167-214.

2. Rosário PW, Ward LS, Carvalho GA, Graf H, Maciel RB, Maciel LMZ, et al. Thyroid nodule and differentiated thyroid cancer: update on the Brazilian consensus. Arq Bras Endocrinol Metabol. 2013;57:240-64.

3. Medvedec M. Thyroid stunning in vivo and in vitro. Nucl Med Commun. 2005;26:731-5.

4. Lees W, Mansberg R, Roberts J, Towson J, Chua E, Turtle J. The clinical effects of thyroid stunning after diagnostic whole-body scanning with $185 \mathrm{MBq}^{131}$. Eur J Nucl Med. 2002;29:1421-7.

5. Lundh $C$, Lindencrona $U$, Postgård $P$, Carlsson $T$, Nilsson $M$, Forssell-Aronsson E. Radiation-induced thyroid stunning: differential effects of $123 \mathrm{I},{ }^{131} \mathrm{I}, 99 \mathrm{mTc}$, and 211 At on iodide transport and NIS mRNA expression in cultured thyroid cells. J Nucl Med. 2009;50:1161-7.

6. Van Nostrand D, Aiken M, Atkins F, Moreau S, Garcia C, Acio E, et al. The utility of radioiodine scans prior to iodine 131 ablation in patients with well-differentiated thyroid cancer. Thyroid. 2009;19:849-55.

7. Cooper DS, Doherty GM, Haugen BR, Kloos RT, Lee SL, Mandel SJ, et al. American Thyroid Association Guidelines Taskforce. Management guidelines for patients with thyroid nodules and differentiated thyroid cancer. Thyroid. 2006;16:109-42. 
8. Chen MK, Yasrebi M, Samii J, Staib LH, Doddamane I, Cheng DW. The utility of $\mathrm{I}-123$ pretherapy scan in I-131 radioiodine therapy for thyroid cancer. Thyroid. 2012;22:304-9.

9. Pacini F, Schlumberger M, Dralle H, Elisei R, Smit JW, WiersingaW. European Thyroid Cancer Taskforce. European consensus for the management of patients with differentiated thyroid carcinoma of the follicular epithelium. Eur J Endocrinol. 2006;154:787-803.

10. Schlumberger M, Pacini F, Wiersinga WM, Toft A, Smit JW, Sanchez Franco F, et al. Follow-up and management of differentiated thyroid carcinoma: a European perspective in clinical practice. Eur J Endocrinol. 2004;151:539-48.

11. McDougall IR. The case for obtaining a diagnostic whole-body scan prior to iodine 131 treatment of differentiated thyroid cancer. Thyroid. 2009;19:811-3.

12. Samuel AM, Rajashekharrao B. Radioiodine therapy for well-differentiated thyroid cancer: a quantitative dosimetric evaluation for thyroid remnant ablation after surgery. J Nucl Med. 1994;35:1944-50.

13. Hammami MM, Bakheet S. Radioiodine breast uptake in nonbreastfeeding women: clinical and scintigraphic characteristics. J Nucl Med. 1996;37:26-31.

14. Datz FL. Cerebral edema following iodine-131 therapy for thyroid carcinoma metastatic to the brain. J Nucl Med. 1986;27:637-40.

15. National Comprehensive Cancer Network (NCCN) 2010, NCCN Guidelines for Treatment of Cancer by Site, Thyroid Carcinoma. Available at: http://www. nccn.org/ professionals/physician_gls/ pdf/thyroid.pdf.
16. Morris LF, Waxman AD, Braunstein GD. Thyroid stunning. Thyroid. 2003;13:333-40.

17. Leger FA, Izembart M, Dagousset F, Barritault L, Baillet G, Chevalier $A$, et al. Decreased uptake of therapeutic doses of 131-iodine after 185-MBq and 123-iodine diagnostic imaging for thyroid remnants in differentiated thyroid carcinoma. Eur J Nucl Med. 1998;25:242-6.

18. Morris LF, Waxman AD, Braunstein GD. The non-impact of thyroid stunning: remnant ablation rates in ${ }^{131} 1$-scanned and non-scanned individuals. J Clin Endocrinol Metab. 2001;86:3507-11.

19. Rosario PWS, Barroso AL, Rezende LL, Padrão EL, Fagundes $T A$, Reis JS, et al. Outcome of ablation of thyroid remnants with 100 mci $(3.7 \mathrm{Gbq})$ 131-iodine in patients with thyroid cancer. Ann Nucl Med. 2005;19:247-50.

20. Dam HQ, Kim SM, Lin HC, Intenzo CM. ${ }^{131}$ I therapeutic efficacy is not influenced by stunning after diagnostic whole-body scanning. Radiology. 2004;232:527-33.

21. Sisson JC, Avram AM, Lawson SA, Gauger PG, Doherty GM. The so-called stunning of thyroid tissue. J Nucl Med. 2006;47:1406-12.

22. Silberstein EB, Alavi A, Balon HR, Becker D, Charkes D, Clarke S, et al. Society of nuclear medicine procedure guideline for therapy of thyroid disease with lodine-131, version 2.0. Available at: http://interactive.snm.org/docs/Therapy\% 20of\% 20Thyroid\% 20Disease\%20with\%20lodine-131\%20v2.0.pdf.

23. Amin A, Amin M, Badwey A. Stunning phenomenon after a radioactive iodine-131 I diagnostic whole-body scan: Is it really a point of clinical consideration? Nucl Med Commun. 2013;34:771-6. 